\title{
Construction and characterization of a cDNA expression library from the endangered Hu sheep
}

\author{
P.-F. Hu ${ }^{1,2 *}$, X.-C. Li ${ }^{1 *}$, H.-K. Liu ${ }^{1}$, W.-J. Guan ${ }^{1}$ and Y.-H. Ma ${ }^{1}$ \\ ${ }^{1}$ Institute of Animal Sciences, Chinese Academy of Agricultural Sciences, \\ Beijing, China \\ ${ }^{2}$ Institute of Special Economic Animal and Plant Sciences, \\ Chinese Academy of Agricutural Sciences, Changchun, China \\ *These authors contributed equally to this study. \\ Corresponding author: W.-J. Guan \\ E-mail: weijunguan301@gmail.com
}

Genet. Mol. Res. 13 (4): 9019-9023 (2014)

Received August 5, 2013

Accepted February 2, 2014

Published October 31, 2014

DOI http://dx.doi.org/10.4238/2014.October.31.16

\begin{abstract}
Hu sheep is one of the most important species in China; it is also listed as one of the 78 nationally protected domestic animals by the Chinese government in 2000. The construction of cDNA expression library of $\mathrm{Hu}$ sheep is of great significance for protecting individual genomes, generating transgenic sheep, and conducting clinical research using cDNA from Hu sheep. In this study, the total RNA from the ear tissue of $\mathrm{Hu}$ sheep was extracted, and a cDNA expression library was constructed using the SMART ${ }^{\mathrm{TM}}$ technique. The titer of amplified cDNA library was $1.09 \times 10^{10} \mathrm{PFU} / \mathrm{mL}$, the rate of recombination was above $91.6 \%$, and the average size of fragments was $1.1 \mathrm{~kb}$. This study has an important significance for the preservation of Hu sheep resources at the genome level.
\end{abstract}

Key words: Hu sheep; cDNA expression library; Endangered animals 


\section{INTRODUCTION}

$\mathrm{Hu}$ sheep is one of the most important species in China; it was listed as one of the 78 nationally protected domestic animals by the Chinese government in 2000. Constructing $\mathrm{Hu}$ sheep cDNA library for the protection of genetic resources, as well as identifying gene functions, has an important genetic significance (Wang et al., 2013).

A cDNA library is a combination of cloned cDNA fragments inserted into a collection of host cells; it refers to the biological developmental stages of the transcriptome. Since cDNAs are produced from fully transcribed mRNAs and contain only the genes expressed of an organism, cDNA libraries are a powerful and useful tool for efficiently identifying gene products (Yang et al., 2012). The construction and analysis of cDNA libraries are considered to be an indispensable tool for functional genomic analysis since these libraries provide considerably detailed information on the genomic mechanisms underlying diverse processes of an organism (Hu et al., 2009; Shao et al., 2009). In this study, the SMART ${ }^{\mathrm{TM}}$ technique was used for producing high-quality and full-length cDNA libraries that preserve the complete $5^{\prime}$ terminal sequence of mRNAs (Du et al., 2007). The establishment and characterization of cDNA library for Chinese Hu sheep can not only help to preserve this nationally protected breed resource but also provide probes for the construction of molecular marker linkage maps. More importantly, it can be used to separate full-length genes and identify their functions (Ye et al., 2012).

\section{MATERIAL AND METHODS}

\section{Animal and tissue collection}

Ear marginal tissue samples of Hu sheep were collected from a Hu sheep conservation farm in Su Zhou, Jiangsu Province of China. The samples were frozen in liquid nitrogen and then used for RNA isolation.

\section{RNA extraction and cDNA library construction}

Total RNA was extracted from 100-mg tissue samples using Trizol reagent (GIBCO, USA). cDNAs were synthesized using a SMART PCR cDNA synthesis kit (Clontech, USA). cDNA expression library was then constructed using SMART ${ }^{\mathrm{TM}}$ cDNA library construction kit (Clontech). The amplified libraries were stored at $-80^{\circ} \mathrm{C}$.

\section{PCR screening of cDNA inserts}

The constructed library was screened using M13 primers to determine the percentage of recombinant clones and ligation efficiency. Efficient ligation of cDNAs to the $\lambda$ TriplEx2 Vector should result in more than $80 \%$ recombinants.

\section{Titering the amplified library}

The titer of the library was determined by incubating $100 \mu \mathrm{L}$ serial dilutions of the 
given recombinant bacteriophage with $200 \mu \mathrm{L}$ of the appropriate host. The plaques were counted, and the titer $(\mathrm{PFU} / \mathrm{mL}$ ) was calculated as follows: $\mathrm{PFU} / \mathrm{mL}=$ (number of plaques $\mathrm{x}$ dilution factor $\left.\times 10^{3} \mu \mathrm{L} / \mathrm{mL}\right) /(\mu \mathrm{L}$ of diluted phage plated).

\section{RESULTS AND DISCUSSION}

SMART technology was used to produce fragments of $300 \mathrm{bp}-4 \mathrm{~kb}$ of the doublestranded cDNA (Figure 1). After the double-stranded cDNA was digested using $S f i$, large cDNA fragments were separated using the Chroma SPIN-400 column; electrophoresis showed that the first 5-, 6-, 7- and 8-eluting cDNA materials were larger than $300 \mathrm{bp}$.

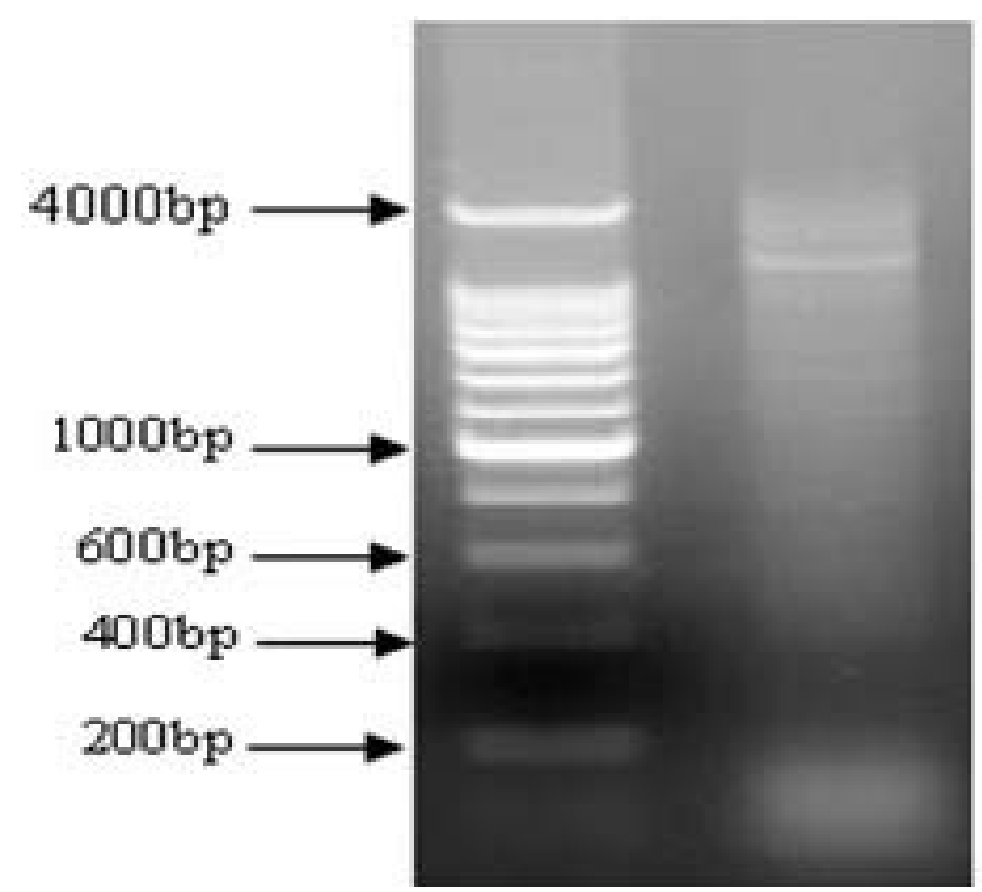

Figure 1. LD-PCR amplification products by agarose gel electrophoresis.

cDNA column fractionation was used to elute and enrich cDNA fragments according to fragment size in a descending order. Since the column should be completely balanced during operation, the column substrate was repeatedly balanced using buffer solution. Further, fractionation might be affected by bubbles in the column substrate, and hence, they were eliminated. Since the cDNA quantity was considerably smaller after fractionation, the collected cDNA was detected using thin agarose gel electrophoresis. The time of electrophoresis was shorter than usual to avoid blurring of the target bands. The separated products were selected according to the size of cDNA fragments, which were estimated by agarose gel electrophoresis; small fragments were discarded because they might affect the ligation efficiency and cDNA library quality (Fülle, 2003). 
Test results showed that the titer of the unamplified cDNA library was $2.71 \times 10^{6} \mathrm{PFU} /$ $\mathrm{mL}$; the titer of the amplified library reached $1.09 \times 10^{10} \mathrm{PFU} / \mathrm{mL}$. In all, 96 phage clones were randomly selected for PCR; $1.0 \%$ agarose gel electrophoresis results showed that 8 clones were empty (including those with fragment length of less than $300 \mathrm{bp}$ ) and 88 were positive. The re-rate was $91.6 \%$, and the average length of the inserted fragment was about $1.1 \mathrm{~kb}$ (Figure 2).

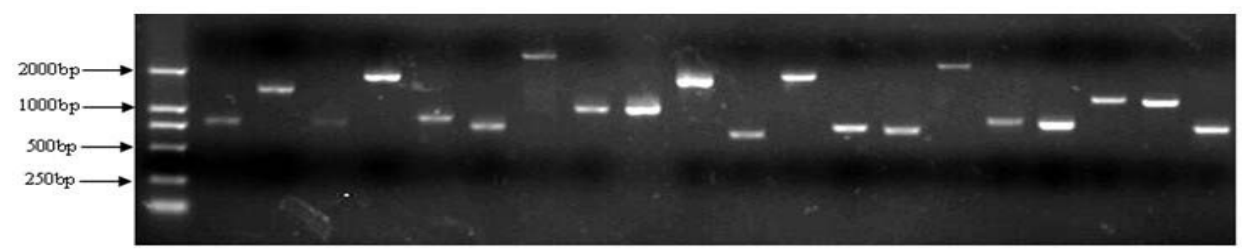

Figure 2. cDNA insert size by PCR detection.

Library titer and recombination rate are 2 important indices for the evaluation of cDNA libraries (Serafica et al., 2005). A cDNA library is constructed to identify more meaningful cDNAs; the comprehensiveness and representativeness would be questionable if the library titer was low. A cDNA library must include almost all reverse transcribed mRNA molecules so that each gene can be cloned. Both in terms of capacity and library insert sizes, the library constructed in this study met the quality requirements, i.e., it had certain integrity of representation and sequence and could be used for further study. The data obtained from our library suggested its comprehensiveness and representativeness since there was diversity of genes in size and occupancy.

A cDNA library was first established by Hofstetter in 1976 (Hofstetter et al., 1976) and developed by Gubler (Gubler et al., 1983). In the early stages, ligation efficiency of plasmid vectors was low, amplification and preservation of vectors were difficult, and insert cDNA fragments were always too short. With the advancement in technical competence, cDNA libraries could be constructed more conveniently and efficiently. Different methods for construction of cDNA libraries were developed: cap retention procedure (CAPture; Edery et al., 1995), oligo-capping method (Suzuki and Sugano, 2003), switching mechanism at $5^{\prime}$ end of RNA transcript (SMART) method (Zhu et al., 2001), cap-trapper method (Carninci et al., 2000), and cap-jumping method (Efimov et al., 2001). Every method had some drawbacks, for example, PCR amplification could affect representative cDNA clones, some genes were difficult to be cloned, plasmid vectors were not suitable for large gene clones, and some methods were time consuming and complicated.

Powerscript ${ }^{\mathrm{TM}} \mathrm{RT}$ reverse transcriptase was used with the SMART method for the construction of full-length cDNA expression library; the process was convenient and time saving (Wellenreuther et al., 2004). This method had some advantages: primarily, a small amount of mRNA was needed, and there was no need for enzyme or chemical reaction before cDNA synthesis, and hence, mRNA degradation was reduced. Furthermore, the ratio of full-length cDNA was relatively high. Therefore, the SMART method has widely been used in medical and genetic studies.

The ear tissue cDNA expression library of Hu sheep constructed using SMART ${ }^{\mathrm{TM}}$ 
technique had good quality. The titer of amplified cDNA library was $1.09 \times 10^{10} \mathrm{PFU} / \mathrm{mL}$, the rate of recombinant was above $91.6 \%$, and the average size of fragments was $1.1 \mathrm{~kb}$. This study has an important significance for the preservation of $\mathrm{Hu}$ sheep resources at the genome level.

\section{ACKNOWLEDGMENTS}

Research supported by the Ministry of Agriculture of China for Transgenic Research Program (\#2013ZX08009-003-006, \#2013ZX08012-002-06), the project National Infrastructure of Animal Germplasm Resources (2013 year), and the earmarked fund for Modern AgroIndustry Technology Research System (\#nycytx-40-01).

\section{REFERENCES}

Carninci P, Shibata Y, Hayatsu N, Sugahara Y, et al. (2000). Normalization and subtraction of cap-trapper-selected cDNAs to prepare full-length cDNA libraries for rapid discovery of new genes. Genome Res. 10: 1617-1630.

Du LX, Liu SF, Zhu J, Li HB, et al. (2007). Construction of SMART cDNA library of sheep ovary and identification of candidate gene by homologous cloning. Sci. Agric. Sin. 6: 1390-1395.

Edery I, Chu LL, Sonenberg N and Pelletier J (1995). An efficient strategy to isolate full-length cDNAs based on an mRNA cap retention procedure (CAPture). Mol. Cell Biol. 15: 3363-3371.

Efimov VA, Chakhmakhcheva OG, Archdeacon J, Fernandez JM, et al. (2001). Detection of the 5'-cap structure of messenger RNAs with the use of the cap-jumping approach. Nucleic Acids Res. 29: 4751-4759.

Fülle HJ (2003). Quality assessment of cDNA libraries. Methods Mol. Biol. 221: 145-153.

Gubler U and Hoffman BJ (1983). A simple and very efficient method for generating cDNA libraries. Gene 25: $263-269$.

Hofstetter H, Schambock A, Van Den Berg J and Weissmann C (1976). Specific excision of the inserted DNA segment from hybrid plasmids constructed by the poly(dA). poly (dT) method. Biochim. Biophys. Acta 454: 587-591.

Hu H, Liu YG, Zhao SM, Deng WD, et al. (2009). Molecular characterization and tissue expression of ovine PSAM6 gene from muscle full-length cDNA library of black-boned sheep. Anim. Biotechnol. 20: 238-241.

Serafica MD, Goto T and Trounson AO (2005). Transcripts from a human primordial follicle cDNA library. Hum. Reprod. 20: 2074-2091.

Shao ZT, Cong X, Yuan JD, Yang GW, et al. (2009). Construction and characterization of a cDNA library from head kidney of Japanese sea bass (Lateolabrax japonicus). Mol. Biol. Rep. 36: 2031-2037.

Suzuki Y and Sugano S (2003). Construction of a full-length enriched and a 5'-end enriched cDNA library using the oligocapping method. Methods Mol. Biol. 221: 73-91.

Wang CL, Ying SJ, Wang ZY, Xing HJ, et al. (2013). Molecular cloning and expression of 17 beta-hydroxysteroid dehydrogenase type 2 gene in Hu sheep. Mol. Biol. Rep. 40: 1073-1080.

Wellenreuther R, Schupp I, Poustka A and Wiemann S (2004). SMART amplification combined with cDNA size fractionation in order to obtain large full-length clones. BMC Genomics 5: 36.

Yang XL, Bai DZ, Qiu W, Dong HQ, et al. (2012). Screening of tissues pooled cDNA library using probes by restricted fragments of BAC positive clones of ovine MHC. Yi. Chuan 34: 887-894.

Ye RS, Pan HB, Yin GF, Huang Y, et al. (2012). Molecular characterization and tissue expression profile of three novel ovine genes: ATP5O, NDUFA12 and UQCRH from muscle full-length cDNA library of black-boned sheep. Mol. Biol. Rep. 39: 5767-5774.

Zhu YY, Machleder EM, Chenchik A, Li R, et al. (2001). Reverse transcriptase template switching: a SMART approach for full-length cDNA library construction. Biotechniques 30: 892-897. 